ORIGINAL RESEARCH

\title{
Physiological Bone Responses in the Fingers After More Than 10 Years of High-Level Sport Climbing: Analysis of Cortical Parameters
}

\author{
Frederik Hahn, MD; Matthias Erschbaumer, MD; Philipp Allenspach, MSc; Kaspar Rufibach, PhD; \\ Andreas Schweizer, MD \\ From the Clinic for Plastic- and Handsurgery, Inselspital, Universital Hospital, Berne, Switzerland (Dr Hahn); the Orthopaedic Department, \\ Balgrist University Hospital, Zurich, Switzerland (Drs Erschbaumer and Schweizer); the Institute of Human Movement Sciences and Sport, \\ Eidgenössische Technische Hochschule Zürich, Zurich, Switzerland (Dr Allenspach); and the Institute for Social and Preventive Medicine, \\ University of Zurich, Zurich, Switzerland (Dr Rufibach).
}

Objective.-Sports activity can induce bone modeling processes with apposition of new bone and changes in bone morphology. Sport climbing places extreme forces and stress on the hands, especially on the bones of the fingers. This study examines sports-induced physiological adaptations of the finger bones of climbers.

Methods.-In this cohort study, the radiographs of 31 high-level (Union Internationale des Associations d'Alpinisme [UIAA] metric scale range 8.33 to 11.33 ), experienced (median 20 years climbing time) adult climbers were compared with those of a control group of 67 patients. Cortical dimensions and variables were measured and analyzed in a total of 330 fingers. An association analysis of climbing-related variables was also performed.

Results.-The climber's bones showed a 25\% higher cortical proportion than those of the control group. On average, the outer cortical width of the climbers' bones was $6 \%$ larger and the medullary canal was $20 \%$ narrower than in the control group $(P<.05)$. The differences between groups were more pronounced in the sagittal plane and more pronounced distally in the fingers. No associations were found between age, climbing experience, climbing level, and the cortical hypertrophy.

Conclusions.-Differences in bone morphology can be observed in the finger bones of adult climbers when compared with controls. Because the differences are more pronounced at the palmar and dorsal cortices, the analysis of the sagittal plane should always be included in future investigations. To evaluate climbing-related factors influencing these adaptive morphologic differences, further studies with larger, more specific study cohorts are needed.

Key words: physiologic bone modeling, cortical bone, mechanical stress, sports climbing, bouldering

\section{Introduction}

Several studies have examined structural changes of human bones after exposure to sports activity. ${ }^{1-4}$ Adaptive processes in bone in the form of hypertrophy or increase in bone mass density due to sports activity have been examined mainly for long bones, namely, femur, humerus, and forearm. In sport climbing, the fingers and hands are exposed to substantial mechanical stress. However, few studies have specifically examined physiologic

Corresponding author: Frederik Hahn, MD, Clinic for Handsurgery, Inselspital, Freiburgstrasse, University of Berne, Berne, Switzerland (e-mail: Frederik.Hahn@insel.ch). adaptive reactions in the fingers. These studies demonstrate that sports-related bone hypertrophy can also be observed in the fingers of climbers. ${ }^{5-8}$

The current study focused specifically on radiographic changes in the cortical bone of the fingers of high-level climbers with $>10$ years of climbing activity. We expected bone modeling with cortical changes to be more pronounced in the sagittal plane (lateral view), as this corresponds to the general stress pattern during rock climbing, during which the main forces are placed in the flexion-extension plane. ${ }^{9}$ We looked specifically at the dorsal and palmar mid-diaphyseal cortices in the sagittal view and analyzed the data for correlations with the bone 
changes previously described for the anterior-posterior view. ${ }^{5-8}$ In the current study, we analyzed anteriorposterior and lateral radiographs of high-level climbers and those of a control group.

As different fingers of the hand are exposed to varying degrees of stress during climbing, we expected stress reactions in the bone to be finger dependent. Furthermore, previous studies have found that bone changes are accentuated more periosteally in younger persons and more endosteally in adults. ${ }^{1,10,11}$ Therefore, we expected the differences in our group of adult climbers to be primarily endosteal. This is the first study to examine systematically all fingers except the thumb in both hands of high-level climbers with anterior-posterior and lateral radiographs. Another aim of the present study was to investigate the potential influence of climbing-specific factors on radiographic adaptations, as first described by Schöffl et al. ${ }^{8}$

\section{Methods}

A group of 31 male adult climbers volunteered for this study after it had been approved by the Institutional Ethics Board. Inclusion criteria for the climbers' participation were climbing experience of $>10$ years, age $>27$ years, and a climbing level $\geq 8.33$ (Union Internationale des Associations d'Alpinisme [UIAA] metric scale). Standardized radiographs (anterior-posterior and lateral views) of all fingers of both hands (except the thumbs) were taken using a positioning device (Figure 1). The control group consisted of the radiographs of 82 fingers of 67 male trauma patients from our hospital archive (Table 1). Three measurements were digitally obtained in the anterior-posterior and lateral views for each phalanx of each finger: length of phalanx, total bone width, and medullary width.

All measurements were done by 2 researchers (A.P., E.M.) according to the protocol described by Bollen and Wright. ${ }^{5}$ In the climbers' group, 3 distal phalanges, wherein the cortex and medullary canal could not be clearly differentiated, were excluded from the study. We then calculated the Barnett-Nordin (BN) index (cortical width/total width $\times 100$ ), ${ }^{12}$ the width ratio (outer cortical width/length of phalanx $\times 100$ ), and the canal ratio (medullary width/length of phalanx $\times 100$ ) to describe the outer and inner bone dimensions, respectively. Note that using ratios alone scattered the differences in size and body weight, which we could not control for within the nonclimber cohort. All 3 variables were calculated for the anterior-posterior and lateral views, and analyzed further. Then, 248 climbers' fingers were compared with 82 control group fingers using the measurements for the
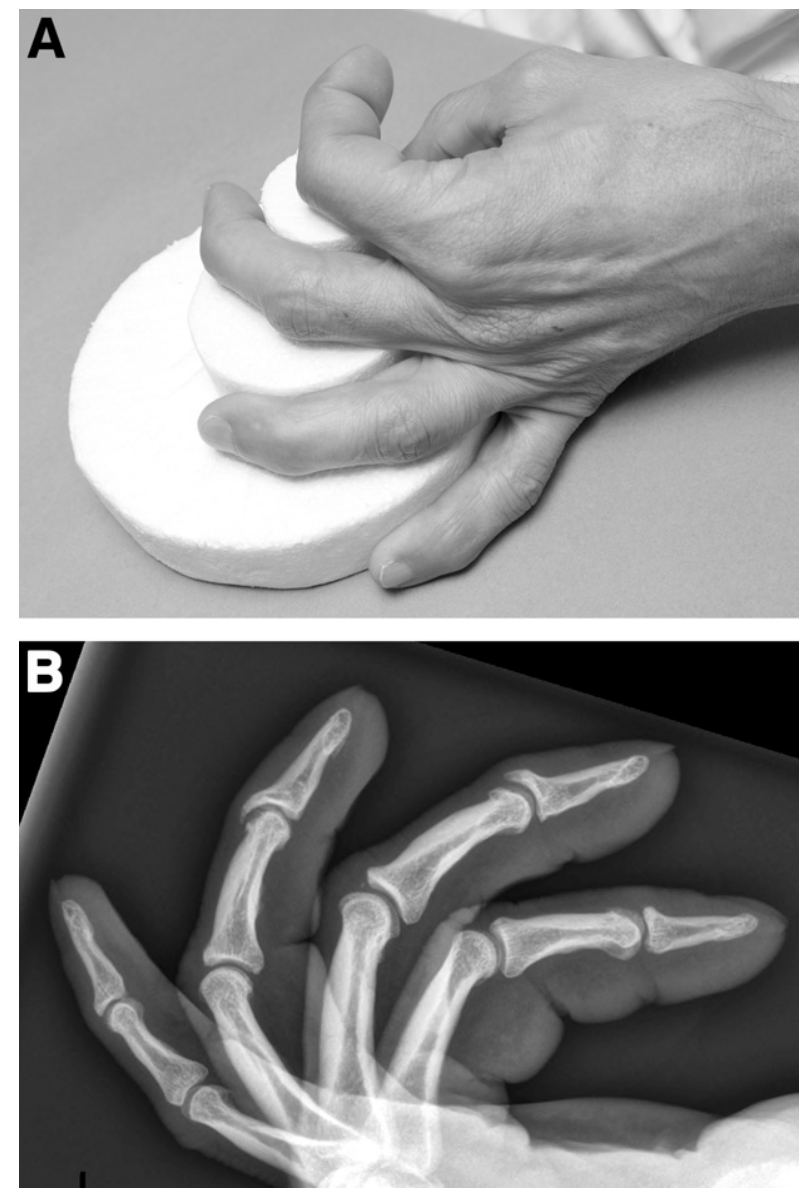

Figure 1. A, Device to obtain standardized lateral radiographs of the fingers. B, Standardized lateral radiographs of the fingers in the climbers' group.

proximal (P1), middle ( $\mathrm{P} 2)$, and distal (P3) phalanx in the anterior-posterior and lateral views.

\section{STATISTICAL ANALYSIS}

Looking at clustered data with dependency between the measurements, we analyzed the data using a linear mixed effects model with a random intercept for each finger tested within each patient. Such a model induces a compound symmetry correlation structure between observations of the same person, namely, it is stipulated that the correlation between any 2 fingers of the same person is the same. The linear mixed effects regression model with random intercept was again used to identify possible influences of climber characteristics (age, years of climbing, climbing level) on the dependent variable, the BN index. All analyses were performed using the program $\mathrm{R}$ ( $\mathrm{R}$ Development Core Team, Vienna, Austria). ${ }^{13}$ The linear mixed models were computed using the function lme in the package nlnme. Statistical tests were per- 
Table 1. Descriptive statistics for climbers and controls

\begin{tabular}{|c|c|c|c|c|c|c|c|c|c|}
\hline \multirow[b]{2}{*}{ Group } & \multicolumn{3}{|c|}{ Age, years } & \multicolumn{3}{|c|}{ Height, cm } & \multicolumn{3}{|c|}{ Mass, $\mathrm{kg}$} \\
\hline & Median & Range & $I Q R$ & Median & Range & $I Q R$ & Median & Range & $I Q R$ \\
\hline Climbers & 36.0 & $30-48$ & 5 & 179 & $167-186$ & 4 & 72.0 & 54-85 & 8.5 \\
\hline Controls & 38.0 & $27-50$ & 10 & NA & NA & & NA & NA & \\
\hline
\end{tabular}

IQR, interquartile range; NA, not available.

formed at a significance level of alpha $=0.05$, and confidence intervals were computed using a confidence level of $95 \%$.

\section{Results}

Descriptive statistics for climbers and control group are provided in Table 1, and climbing-specific variables in Table 2. We found statistically significant differences between the cortical proportions of the bones of climbers and those of the control bones. These differences were associated with the variable "phalanx" (P1, P2, P3). There were no associations with the variables "side" (left hand, right hand) or "finger" (index, middle, ring, small finger); thus, these 2 variables were excluded from the presentation in Table 3. Table 3 displays the means for climbers $(n=31)$ and controls $(n=67)$ adjusted for the interindividual dependencies. The 3 variables- $\mathrm{BN}$ index, outer width ratio, and medullary canal ratio-were differentiated for the phalanges (P1, P2, P3). The absolute difference and relative (\%) differences between the groups were computed from a linear mixed effects model that adjusts for the clustering in the data. Positive values correspond to higher means for the climbers; negative values indicate that climbers have lower means for the corresponding variable.

The data show substantial differences between the 2 groups for the 3 main variables. Two general characteristics can be identified. First, the differences in bone morphology between the groups were more pronounced in the distal phalanges of the fingers $(\mathrm{P} 3>\mathrm{P} 2>\mathrm{P} 1)$. Second, the differences between climbers and controls were higher for the lateral view than for the anteriorposterior view. These 2 characteristics are consistent for all data. Climbers had higher values for all phalanges in the anterior-posterior and lateral views for the BN index and the width ratio than the controls. The differences were greater for the $\mathrm{BN}$ index (14.7\% to $49.5 \%)$ than for the width ratio $(0.7 \%$ to $13.3 \%)$. The medullary canal (canal ratio) was narrower in climbers $(-12.3 \%$ to $-32.1 \%$ ). These differences were 1.9- to 4.0 -fold higher compared with the differences in width ratio. In summary, climbers had a $25 \%$ higher cortical proportion than the controls. Their fingers were approximately $6 \%$ wider and the medullary canals approximately $20 \%$ narrower than in the control fingers. The relative contribution of periosteal expansion and endocortical contraction responsible for the differences between climbers and controls was 22:78.

Figure 2 illustrates the higher values of the $\mathrm{BN}$ index for the lateral view $\left(\mathrm{BN}_{\text {lat }}\right)$ and anterior-posterior view $\left(\mathrm{BN}_{\mathrm{ap}}\right)$ in the fingers of climbers. However, there was only a moderate correlation between the $\mathrm{BN}_{\mathrm{ap}}$ and $\mathrm{BN}_{\text {lat }}$ $(r=0.58)$. A linear mixed effects regression model was used to analyze the influence of the climbing-specific variables-age, years of climbing, climbing level in sport climbing, and climbing level in bouldering-on $\mathrm{BN}_{\text {lat }}$ index. No significant effects were found.

Table 2. Summary statistics for climbing-specific factors

\begin{tabular}{lccc}
\hline \multicolumn{1}{c}{ Variable } & $n$ & Median & Range \\
\hline Years of climbing $^{\prime}$ & 31 & 20.00 & $10-34$ \\
Highest level in sport climbing $^{a}$ & 31 & 9.66 & $8.66-11.33$ \\
Highest level in bouldering $^{a}$ & 25 & 9.33 & $8.33-10.66$ \\
Maximal hours of training per week $_{\text {Hours of indoor sport climbing per week }}$ & 29 & 20.00 & $8-35$ \\
Hours of outdoor sport climbing per week $_{\text {Hours of indoor bouldering per week }}$ & 29 & 0.00 & $0-8$ \\
Hours of outdoor bouldering per week & 29 & 5.00 & $0-18$ \\
& 29 & 3.50 & $0-20$ \\
\hline
\end{tabular}

${ }^{a}$ Union Internationale des Associations d'Alpinisme (UIAA) metric scale. 
Table 3. Results for differences between climbers and controls

\begin{tabular}{|c|c|c|c|c|c|c|c|c|c|}
\hline Variable & Phalanx & $\begin{array}{c}\text { No. of climbers } \\
\text { and controls }\end{array}$ & $\begin{array}{l}\text { No. of } \\
\text { fingers }\end{array}$ & $\begin{array}{l}\text { Mean } \\
\text { control }\end{array}$ & $\begin{array}{c}\text { Mean } \\
\text { climbers }\end{array}$ & $\begin{array}{c}\text { Diff } \\
\text { absolute }\end{array}$ & Diff \% & $95 \% C I$ & $P$ value \\
\hline \multicolumn{10}{|l|}{$\mathrm{BN}$ index } \\
\hline \multirow[t]{3}{*}{ Ap } & $\mathrm{P} 1$ & 97 & 322 & 53.37 & 61.22 & 7.85 & 14.71 & $4.69,11.00$ & $<.001$ \\
\hline & $\mathrm{P} 2$ & 97 & 322 & 49.61 & 58.77 & 9.16 & 18.48 & $5.18,13.15$ & $<.001$ \\
\hline & P3 & 95 & 318 & 40.75 & 53.27 & 12.52 & 30.73 & $8.87,16.16$ & $<.001$ \\
\hline \multirow[t]{3}{*}{ Lat } & $\mathrm{P} 1$ & 98 & 329 & 59.62 & 68.77 & 9.15 & 15.35 & $6.96,11.34$ & $<.001$ \\
\hline & $\mathrm{P} 2$ & 98 & 329 & 57.25 & 71.51 & 14.25 & 24.90 & $11.63,16.87$ & $<.001$ \\
\hline & P3 & 96 & 327 & 44.86 & 67.05 & 22.18 & 49.45 & $19.04,25.33$ & $<.001$ \\
\hline \multicolumn{10}{|l|}{ Width ratio } \\
\hline \multirow[t]{3}{*}{ Ap } & $\mathrm{P} 1$ & 97 & 322 & 23.52 & 24.52 & 0.99 & 4.22 & $0.06,1.92$ & .039 \\
\hline & $\mathrm{P} 2$ & 97 & 322 & 31.21 & 32.90 & 1.69 & 5.42 & $0.52,2.86$ & .0058 \\
\hline & P3 & 95 & 318 & 28.27 & 28.48 & 0.21 & 0.74 & $-1.01,1.43$ & .74 \\
\hline \multicolumn{10}{|l|}{ Lat } \\
\hline & $\mathrm{P} 1$ & 97 & 321 & 15.52 & 16.89 & 1.38 & 8.87 & $0.87,1.88$ & $<.001$ \\
\hline & $\mathrm{P} 2$ & 97 & 321 & 20.16 & 21.63 & 1.48 & 7.33 & $0.69,2.27$ & .0004 \\
\hline & P3 & 94 & 316 & 19.66 & 22.29 & 2.60 & 13.35 & $1.69,3.56$ & $<.001$ \\
\hline \multicolumn{10}{|l|}{ Canal ratio } \\
\hline \multirow[t]{3}{*}{ Ap } & $\mathrm{P} 1$ & 97 & 322 & 10.89 & 9.55 & -1.34 & -12.33 & $-2.13,-0.56$ & .0011 \\
\hline & $\mathrm{P} 2$ & 97 & 322 & 15.72 & 13.65 & -2.07 & -13.15 & $-3.49,-0.65$ & .0052 \\
\hline & P3 & 95 & 318 & 16.88 & 13.58 & -3.30 & -19.54 & $-4.74,-1.86$ & $<.001$ \\
\hline \multicolumn{10}{|l|}{ Lat } \\
\hline & $\mathrm{P} 1$ & 97 & 321 & 6.31 & 5.25 & -1.06 & -16.81 & $-1.50,-0.62$ & $<.001$ \\
\hline & $\mathrm{P} 2$ & 97 & 321 & 8.69 & 6.17 & -2.53 & -29.08 & $-3.23,-1.82$ & $<.001$ \\
\hline & P3 & 94 & 316 & 10.98 & 7.46 & -3.52 & -32.06 & $-4.52,2.52$ & $<.001$ \\
\hline
\end{tabular}

Diff, difference; BN, Barnett-Nordin; Ap, anterior-posterior; Lat, lateral.

\section{Discussion}

Cortical reactions due to mechanical stress during sports activity have been described mainly for the femoral and humeral bones. ${ }^{1,14}$ Studies with cohorts of climbers confirmed that these changes can be also observed in the small bones of the fingers in the form of cortical hypertrophy. $5,7,8,15$ The present study is the first to specifically examine these adaptive reactions in the fingers of climbers in investigating the radiographs of all long fingers of both hands in the anterior-posterior and lateral views.

Cortical hypertrophy in the anterior-posterior view has been described by Bollen and Wright ${ }^{5}$ and by Schöffl et al. ${ }^{7,8}$ Additionally, the present study showed that hypertrophy not only exists in the lateral view at the dorsal and palmar cortices but also that it is even more pronounced there. This finding correlates with the specific grip positions of the fingers during climbing. Here, the mechanical forces are exerted mainly in the sagittal plane in the form of compressive and tensile forces, respectively, to the dorsal and palmar cortices. ${ }^{9}$ Although the fingers are not all exposed to the same forces during climbing, the observed cortical differences affected all fingers in the same way and to the same extent. Interestingly, we found a correlation between the cortical differences and the location within the finger (proximal, middle, distal phalanx). All differences observed between climbers and controls were greater distally ( $\mathrm{P} 3>\mathrm{P} 2>\mathrm{P} 1)$, suggesting that cortical stress reactions are more pronounced distally.

Periosteal expansion as a result of physical exercise has been reported for the growing skeleton and endosteal apposition of bone for the adult bone. ${ }^{1,16,2}$ The medullary canal in our group of adult climbers was between $12 \%$ and $32 \%$ smaller than that in the bones of the control group, a finding that is consistent with the results from the studies discussed. ${ }^{3,17}$ However, that only explained $78 \%$ of the differences in the lateral $\mathrm{BN}$ index. The balance of the differences is the result of a difference in cortical width from $4 \%$ to $13 \%$, with climbers having thicker phalanges (Figure 3).

Time seems to be an important factor when looking at adaptive reactions of the skeleton to physical exercise. In their 5-year follow-up study, Schöffl et $\mathrm{al}^{8}$ showed a trend for an increase of the $\mathrm{BN}$ index (anterior-posterior view) for the 3 study cohorts, although it was not significant. Furthermore, they did not find significant differences between elite climbers and recreational climbers for the anterior-posterior $\mathrm{BN}$ index. ${ }^{8}$ With a median of 


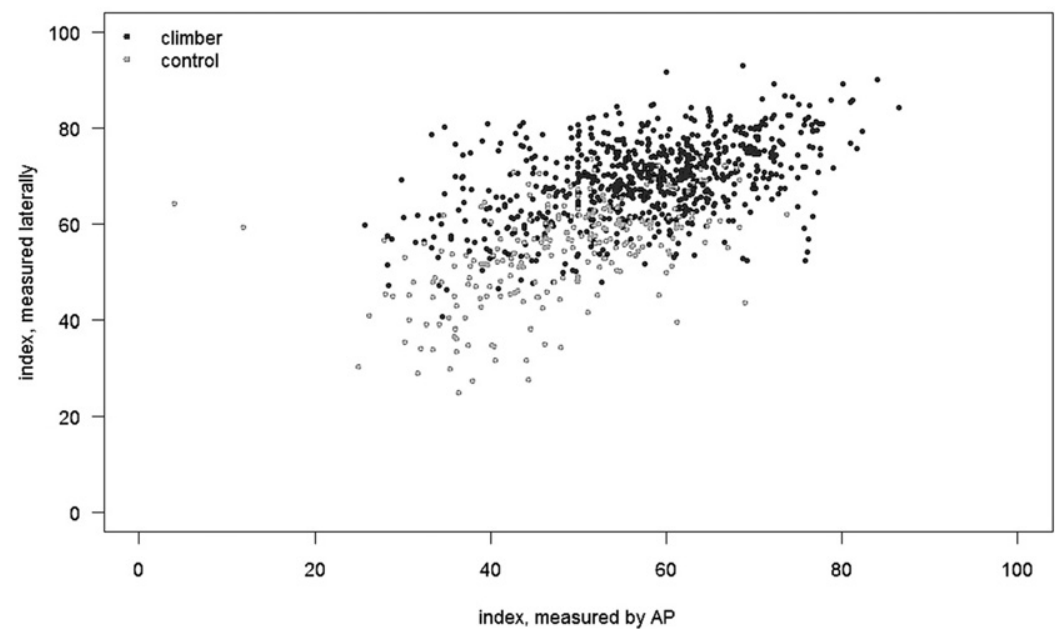

Figure 2. Correlation between the Barnett-Nordin $(\mathrm{BN})$ index in the anteroposterior view $\left(\mathrm{BN}_{\mathrm{ap}}\right)$ and the lateral view $\left(\mathrm{BN}_{\mathrm{lat}}\right)$ for climbers $(\mathrm{black}$ dots) and controls (gray dots).

20 years of climbing activity, our climbers were more distinct from the control group of nonclimbers. That, together with our analysis of the lateral view, might explain the differences between our results and those of Schöffl et al. ${ }^{8}$

Schöffl et $\mathrm{al}^{8}$ found a significant influence of climbingspecific variables on the development of radiographic stress reactions for their group of elite and recreational climbers. However, for the group of elite climbers only, these differences were not significant. ${ }^{8} \mathrm{We}$, too, found no significant influence for the climbing-specific factors of age, years of climbing, and climbing level in our group of elite climbers. Our climbers, with their mean climbing activity of 20 years and just slight differences in ability levels, were probably too homogenous to differentiate the cohort internally.

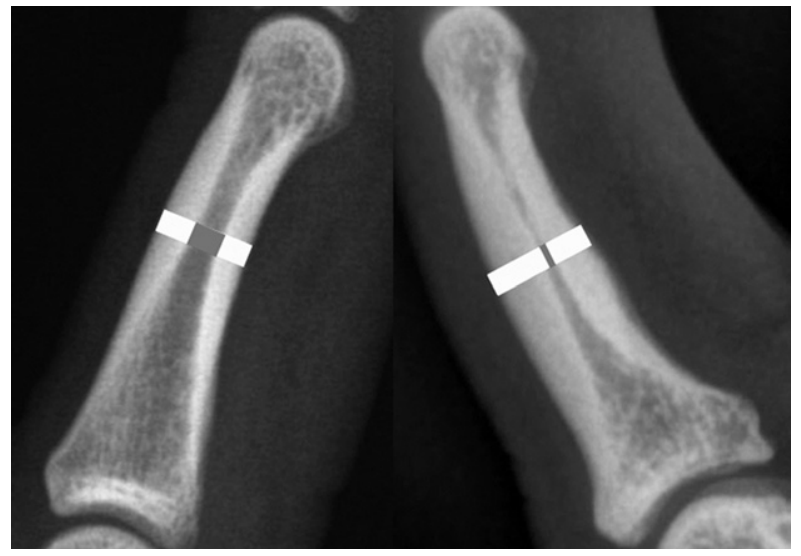

Figure 3. Increased cortical thickness with greater bone diameter and reduced medullary space in climbers (right) compared with controls (left).

\section{Conclusions}

This investigation of cortical parameters in the fingers of high-level climbers demonstrates significant differences in cortical proportions compared with controls. These differences are more pronounced in the distal phalanges $(\mathrm{P} 3>\mathrm{P} 2>\mathrm{P} 1)$ and affect all long fingers (digits II through V) in the same manner. The observed cortical hypertrophy is more pronounced in the lateral view at the dorsal and palmar cortices in the form of endosteal contraction (78\%) and periosteal expansion (22\%).

\section{Acknowledgments}

We would like to thank Lisa Peterson for her linguistic help and for proofreading the manuscript.

\section{References}

1. Bass SL, Saxon L, Daly RM, et al. The effect of mechanical loading on the size and shape of bone in pre-, peri-, and postpubertal girls: a study in tennis players. $J$ Bone Miner Res. 2002;17:2274-2280.

2. Daly RM. The effect of exercise on bone mass and structural geometry during growth. Med Sport Sci. 2007;51: 33-49.

3. Haapasalo H, Kontulainen S, Sievanen H, Kannus P, Jarvinen M, Vuori I. Exercise-induced bone gain is due to enlargement in bone size without a change in volumetric bone density: a peripheral quantitative computed tomography study of the upper arms of male tennis players. Bone. 2000;27:351-357.

4. Kontulainen SA, Hughes JM, Macdonald HM, Johnston JD. The biomechanical basis of bone strength development during growth. Med Sport Sci. 2007;51:13-32. 
5. Bollen SR, Wright V. Radiographic changes in the hands of rock climbers. Br J Sports Med. 1994;28:185-186.

6. Heuck A, Hochholzer T, Keinath C. [Die MRT von Hand und Handgelenk bei Sportkletterern.] Radiologe. 1992;32: 248-254.

7. Schoffl V, Hochholzer T, Imhoff A. Radiographic changes in the hands and fingers of young, high-level climbers. Am J Sports Med. 2004;32:1688-1694.

8. Schoffl VR, Hochholzer T, Imhoff AB, Schoffl I. Radiographic adaptations to the stress of high-level rock climbing in junior athletes: a 5-year longitudinal study of the German Junior National Team and a group of recreational climbers. Am J Sports Med. 2007;35:86-92.

9. Schweizer A. Biomechanical properties of the crimp grip position in rock climbers. J Biomech 2001;34:217-223.

10. Ruff CB. Body size, body shape, and long bone strength in modern humans. J Hum Evol. 2000;38:269-290.

11. Ward KA, Roberts SA, Adams JE, Mughal MZ. Bone geometry and density in the skeleton of pre-pubertal gymnasts and school children. Bone. 2005;36:1012-1018.
12. Barnett E, Nordin BE. The radiological diagnosis of osteoporosis: a new approach. Clin Radiol. 1960;11: $166-174$.

13. R Developement Core Team. R: A language and environment for statistical computing. Vienna, Austria: R Foundation for Statistical Computing; 2010.

14. MacKelvie KJ, Petit MA, Khan KM, Beck TJ, McKay HA. Bone mass and structure are enhanced following a 2-year randomized controlled trial of exercise in prepubertal boys. Bone. 2004;34:755-764.

15. Sylvester AD, Christensen AM, Kramer PA. Factors influencing osteological changes in the hands and fingers of rock climbers. J Anat. 2006;209:597-609.

16. Bradney M, Pearce G, Naughton G, et al. Moderate exercise during growth in prepubertal boys: changes in bone mass, size, volumetric density, and bone strength. A controlled prospective study. J Bone Miner Res. 1998;13:1814-1821.

17. Jones HH, Priest JD, Hayes WC, Tichenor CC, Nagel DA. Humeral hypertrophy in response to exercise. J Bone Joint Surg Am. 1977;59:204-208. 